\title{
Escleritis y anticuerpos antipéptido cíclico citrulinado como presentación inicial de artritis reumatoide
}

\section{Scleritis and anti-cyclic citrullinated peptide antibody as initial presentation of rheumatoid arthritis}

\author{
Matilde Ruiz-Cruz, ${ }^{\star}$ Claudia Hübbe-Tena, ${ }^{\ddagger}$ Carolina Prado-Larrea, ${ }^{\S}$ \\ Rashel Cheja-Kalb," Luz Elena Concha-del-Río"
}

Citar como: Ruiz-Cruz M, Hübbe-Tena C, Prado-Larrea C, Cheja-Kalb R, Concha-del-Río LE. Escleritis y anticuerpos antipéptido cíclico citrulinado como presentación inicial de artritis reumatoide. An Med (Mex). 2020; 65 (4): $262-269$.

https://dx.doi.org/10.35366/97463

\section{RESUMEN}

Introducción: La artritis reumatoide es una enfermedad crónica autoinmune que involucra de manera primaria a las articulaciones, siendo la afección ocular severa parte de las manifestaciones extraarticulares. En estos casos se ha encontrado una fuerte asociación con la presencia de anticuerpos antipéptido cíclico citrulinado. Objetivo: Describir la presencia de afección ocular inflamatoria (escleritis, esclerouveítis, escleritis difusa) con anticuerpos antipéptido cíclico citrulinado positivo y ausencia de manifestaciones articulares, como manifestación temprana de casos que desarrollan posteriormente artritis reumatoide. Material y métodos: Serie de casos retrospectiva, observacional y descriptiva. Se revisaron expedientes clínicos con diagnóstico de escleritis que acudieron a la Clínica de

\section{ABSTRACT}

Introduction: Rheumatoid arthritis is a chronic autoimmune disease that primarily involves joints, with severe eye disease being part of the extra-articular manifestations. In these patients, it has been described a strong association with the presence of anticyclic citrullinated peptide antibodies. Objective: To describe ocular disease (scleritis, sclerouveitis, diffuse scleritis) with anticyclic citrullinated peptide antibodies and the absence of joint manifestations as an early presentation of patients who later develop rheumatoid arthritis. Material and methods: Retrospective, observational and descriptive case-series. Medical records of patients diagnosed with scleritis who attended the Inflammatory Eye Disease Clinic of the Asociación para Evitar la Ceguera from 2010-20, were reviewed. Results: Five patients
* Oftalmología; Cirugía de Retina y Vítreo; Uveítis e Inflamación Ocular; Maestra en Ciencias Médicas, Instituto Nacional de Ciencias Médicas y Nutrición Salvador Zubirán-UNAM; Sistema Nacional de Investigadores; Médico adscrito a la Clínica de Enfermedades Inflamatorias Oculares en la Asociación para Evitar la Ceguera IAP; Universidad La Salle; Centro Médico ABC Campus Santa Fe. Instituto de Oftalmología Conde de Valenciana IAP. México.

₹ Reumatología; Médico adscrito a la Clínica de Enfermedades Inflamatorias Oculares en la Asociación para Evitar la Ceguera; Universidad La Salle. México.

$\S$ Oftalmología; Glaucoma; Médico adscrito al Servicio de Glaucoma en la Asociación para Evitar la Ceguera; UNAM; Centro Médico ABC Campus Santa Fe. Instituto de Oftalmología Conde de Valenciana IAP. México.

I Oftalmología; Uveítis e Inflamación Ocular; Médico adscrito a la Clínica de Enfermedades Inflamatorias Oculares en la Asociación para Evitar la
Ceguera; Universidad Anáhuac; Centro Médico ABC Campus Santa Fe. Instituto de Oftalmología Conde de Valenciana IAP. México.

" Oftalmología; Uveítis e Inflamación Ocular; Jefa de la Clínica de Enfermedades Inflamatorias Oculares en la Asociación para Evitar la Ceguera; Universidad Autónoma de Querétaro. México.

Recibido para publicación: 06/09/2020. Aceptado: 17/11/2020.

Correspondencia: Matilde Ruiz-Cruz

Av. Vasco de Quiroga Núm. 4001, Torre A In situ, quinto piso, Col. Las Tinajas, 05370, Cuajimalpa de Morelos, CDMX.

Teléfono: 55 1664-7276

E-mail: mruizcgala@yahoo.com.mx 
Enfermedades Inflamatorias Oculares de la Asociación para Evitar la Ceguera, del 2010-2020. Resultados: Se incluyeron cinco casos que debutaron con sintomatología oftalmológica inflamatoria (escleritis nodular o difusa, esclerouveítis, escleromalacia) sin sintomatología articular. Todas las pacientes tuvieron anticuerpos antipéptido cíclico citrulinado positivo, dos con valores de factor reumatoide fuera de lo normal durante su evolución y ninguna cumplía con los criterios de la clasificación del American College of Rheumatology/European League Against Rheumatism para artritis reumatoide a la presentación. Durante su evolución, tres desarrollaron artritis reumatoide. Todas las pacientes iniciaron tratamiento con esteroide vía oral y cuatro con fármacos modificadores de la enfermedad. Conclusiones: Es importante el manejo multidisciplinario entre reumatólogos y oftalmólogos en casos que debutan con antipéptido cíclico citrulinado positivo y alteraciones oculares, sin presencia de manifestaciones articulares con la finalidad de instaurar un tratamiento temprano y evitar complicaciones oculares.

Palabras clave: Artritis reumatoide, escleritis, anticuerpos anti-PCC.

Nivel de evidencia: IV who presented with ocular manifestations (nodular or diffuse scleritis, sclerouveitis, scleromalacia) without rheumatoid arthritis symptoms were included. All patients were positive for anticyclic citrullinated peptide antibodies, two patients had abnormal rheumatoid factor and none of them met the American College of Rheumatology/European League Against Rheumatism 2010 classification criteria for rheumatoid arthritis at baseline. Throughout follow-up, three patients developed rheumatoid arthritis. All patients started with oral steroids treatment and disease-modifying anti-rheumatic drugs in four of them. Conclusions: A multidisciplinary approach between rheumatologist and ophthalmologist is essential in patients who debut with positive anticyclic citrullinated peptide antibodies and only ocular involvement, without joint manifestations, in order to establish early treatment and avoid ocular complications.

Keywords: Rheumatoid arthritis, scleritis, anti-CCP antibodies.

Level of evidence: $I V$

\section{INTRODUCCIÓN}

La artritis reumatoide (AR) es una de las enfermedades crónicas más prevalentes caracterizada por una inflamación simétrica de las articulaciones, con destrucción de cartílago y erosión ósea que ocasiona una discapacidad importante en las personas que la padecen. ${ }^{1}$ Involucra de manera primaria a las articulaciones, pero también presenta manifestaciones extraarticulares (nódulos reumatoideos, afección pulmonar, vasculitis y otras comorbilidades sistémicas). ${ }^{2}$

El factor reumatoide (FR) es un autoanticuerpo en contra de la porción de fragmento cristalizable (Fc) de la IgG y se encuentra en un $70-80 \%$ de los casos con AR correlacionándose con mayor enfermedad articular, así como con manifestaciones extraarticulares; a su vez, la presencia de autoanticuerpos antipéptido cíclico citrulinado (anti-PCC) tiene un alto valor predictivo para la progresión radiográfica y desarrollo de AR erosiva, así como de la presencia de manifestaciones extraarticulares. 3,4

Se sabe que estos autoanticuerpos anti-PCC pueden aparecer hasta 10 años previos a los datos clínicos articulares en casos con AR. ${ }^{5,6}$ Éstos pueden unirse a residuos proteicos citrulinados de diversas proteínas propias (colágena tipo II, histonas, fibronectina, fibrinógeno, vimentina y enolasas). ${ }^{1,7-9}$

La detección de anticuerpos anti-PCC ha surgido como el marcador diagnóstico de preferencia para AR, según los criterios del American College of Rheumatology, debido a que tiene una sensibilidad del
$66 \%$ y una especificidad del $90.4 \%$ en comparación con la del FR que es de 71.6 y $80.3 \%$ respectivamente. ${ }^{10}$ Debido a la rápida evolución en el tipo de pruebas para detectar anti-PCC, las de segunda y tercera generación han mejorado ligeramente la sensibilidad siendo de 68-79\% con especificidades del 86-96\%. ${ }^{11}$

Las manifestaciones extraarticulares (EA) en la AR se presentan en un 18-41\% de los casos, pudiendo preceder a la sinovitis. ${ }^{12}$ Dentro de las manifestaciones EA de AR, se menciona a la enfermedad cardiaca como principal causa de muerte; la escleritis y vasculitis de retina son parte de las manifestaciones EA asociadas con vasculitis reumatoide. Está reportado que la mortalidad en el grupo de sujetos con manifestaciones EA es mayor que en el grupo de casos con AR sin manifestaciones EA y mayor que en la población general. ${ }^{13}$

La esclera forma la capa externa del ojo y está constituida principalmente por colágena tipo I y en menor proporción los tipos III, V y VI además de dermatán sulfato. Es un tejido avascular, dependiendo su aporte sanguíneo del plexo epiescleral profundo. ${ }^{14}$ Por lo general, la inflamación de la esclera o escleritis conlleva buscar alguna enfermedad sistémica que amerite tratamiento con inmunosupresores o agentes biológicos. ${ }^{15}$

En un estudio retrospectivo de 196 pacientes, $39 \%$ tuvieron manifestaciones oculares típicas de AR, la más frecuente fue el ojo seco (28\%) y sólo un $2 \%$ presentaron escleritis. ${ }^{16}$ Otros autores han reportado una incidencia variable de escleritis de $0.67-33 \%$ en pacientes con AR. ${ }^{17}$ 
Los casos que tuvieron AR con afección ocular presentaron un promedio de duración de la enfermedad mayor (5.4 \pm 2.7 años) en comparación con los que no tuvieron afección ocular $(2.1 \pm 1.6$ años). ${ }^{16}$ Otra manifestación EA de la AR es la queratitis ulcerativa periférica (QUP), que junto con la escleritis son las dos manifestaciones oftalmológicas más severas, ambas asociadas con un aumento en la mortalidad. ${ }^{18}$

El objetivo de este estudio es describir la presencia de afección ocular (escleritis, esclerouveítis, escleritis difusa) con anti-PCC+ (y ausencia de manifestaciones articulares) como primera manifestación temprana de pacientes que evolucionan al desarrollo de AR.

\section{MATERIAL Y MÉTODOS}

Serie de casos de cinco pacientes proveniente de una cohorte retrospectiva $(n=145)$ de casos que acuden a la Asociación para Evitar la Ceguera (APEC) en México, a la Clínica de Enfermedades Inflamatorias Oculares con diagnóstico de escleritis (datos de dolor ocular y ojo rojo) de los años 2010 al 2020. Se incluyeron edad, género, lateralidad ocular, tipo de escleritis (anterior difusa, anterior nodular, posterior, anterior con necrosis y esclerouveítis), tipo de tratamiento instaurado, recurrencias, tiempo de seguimiento, agudeza visual, así como enfermedad sistémica o reumatológica asociada antes-durante-después del tratamiento, la cual fue diagnosticada por clínica y/o con laboratorios y/o con imágenes de gabinete valorada por una reumatóloga experta (CHT) para determinar valores (score) de acuerdo con los criterios de la clasificación del American College of Rheumatology/ European League Against Rheumatism (ACR/EULAR), así como el grado de actividad de la enfermedad (Disease Activity Score = DAS28) en caso de que la presentaran. ${ }^{19,20}$

Esta investigación cuenta con la aprobación de los comités de ética e investigación de la APEC cumpliendo con los lineamientos de la declaración de Helsinki, titulado «Prevalencia de hallazgos angiográficos asociados a vasculitis de retina en pacientes con escleritis anterior activa secundaria a enfermedades reumatológicas» con número de protocolo asignado por los comités UV-18-03.

Se realizaron exámenes de laboratorio basales (al momento del diagnóstico de la afección ocular) y después de seguimiento: FR, anti-PCC, velocidad de sedimentación globular (VSG), proteína $\mathrm{C}$ reactiva (PCR), biometría hemática $(\mathrm{BH})$, química sanguínea (QS), pruebas de funcionamiento hepático $(\mathrm{PFH})$, anticuerpos anticitoplasma de neutrófilos (ANCA), anticuerpos antinucleares (ANA), así como para descartar etiología infecciosa (PPD, VDRL, FTA-Abs y VIH). En todos los pacientes se solicitaron radiografías de manos y pies (anteroposteriores/oblicuas) al momento de la manifestación ocular para determinar si existían cambios sugestivos de AR. Métodos estadísticos: estadística descriptiva.

\section{RESULTADOS}

En esta serie de cinco casos, el $100 \%$ fueron mujeres, con una mediana de edad de 53 años (rango 34 a 77) al momento de presentar sintomatología oftalmológica (escleritis nodular o difusa, esclerouveítis, escleromalacia). Las pacientes referían de una semana a tres meses de evolución con los síntomas oculares previo al ingreso para su revisión oftalmológica y abordaje sistémico. En cuanto a patología sistémica basal, un caso tenía diabetes mellitus tipo 2 (DM2), uno hipertensión arterial sistémica (HTA) y dos padecían osteopenia. Los datos demográficos y de laboratorio, manifestaciones oftalmológicas y evolución en el tiempo se muestran en la Tabla 1.

Todas tuvieron el anti-PCC +, ya sea con la manifestación oftalmológica o durante su seguimiento; en cuanto a los hallazgos radiográficos, ninguna cumplía con los criterios para AR al momento de la manifestación ocular, presentando únicamente osteopenia $\mathrm{u}$ osteoartrosis leve.

Los estudios de laboratorio para descartar otras patologías autoinmunes, así como infecciosas, fueron negativos. De nuestra serie de casos, al diagnóstico de escleritis o esclerouveítis, la PCR se encontraba elevada en tres pacientes; sólo una tuvo rangos por fuera de lo normal (ajustada por género y edad) en la VSG y sólo una tuvo FR + al momento de la manifestación oftalmológica.

En cuanto a los síntomas articulares, las cinco negaban presencia de artralgias al momento de la manifestación oftalmológica. Con respecto al tratamiento sistémico recibido, todas iniciaron esteroide vía oral (prednisona $=\mathrm{PDN}$ ); cuatro iniciaron metotrexato (MTX) y una azatioprina (AZT). A pesar del tratamiento previamente descrito, tres tuvieron afección ocular bilateral en diferentes tiempos del seguimiento, una de ellas con tres recaídas en la inflamación ocular (paciente \#3). El inicio de tratamiento con inmunosupresor (MTX o AZT) fue variado, siendo en una paciente al mes de su ingreso, en dos a los dos meses, en una a los siete meses y la última lo inició a los dos años tres meses después de la mani- 
festación oftalmológica. A continuación, se describen los tres casos más representativos.

Caso 1: mujer de 53 años con antecedente de HTA, prediabetes, hipotiroidismo subclínico y esteatosis hepática. Inició con ojo derecho rojo tres meses previos, diagnosticándose escleritis anterior difusa (EAD) (Figura 1) y uveítis anterior (esclerouveítis). Negó síntomas articulares y la exploración sistémica fue normal. En los estudios de laboratorio presentó FR y anti-PCC positivos, VSG $=33 \mathrm{~mm} / \mathrm{h}$ (ref. $0-15$

Tabla 1: Características demográficas y de laboratorio; manifestaciones oftalmológicas y evolución.

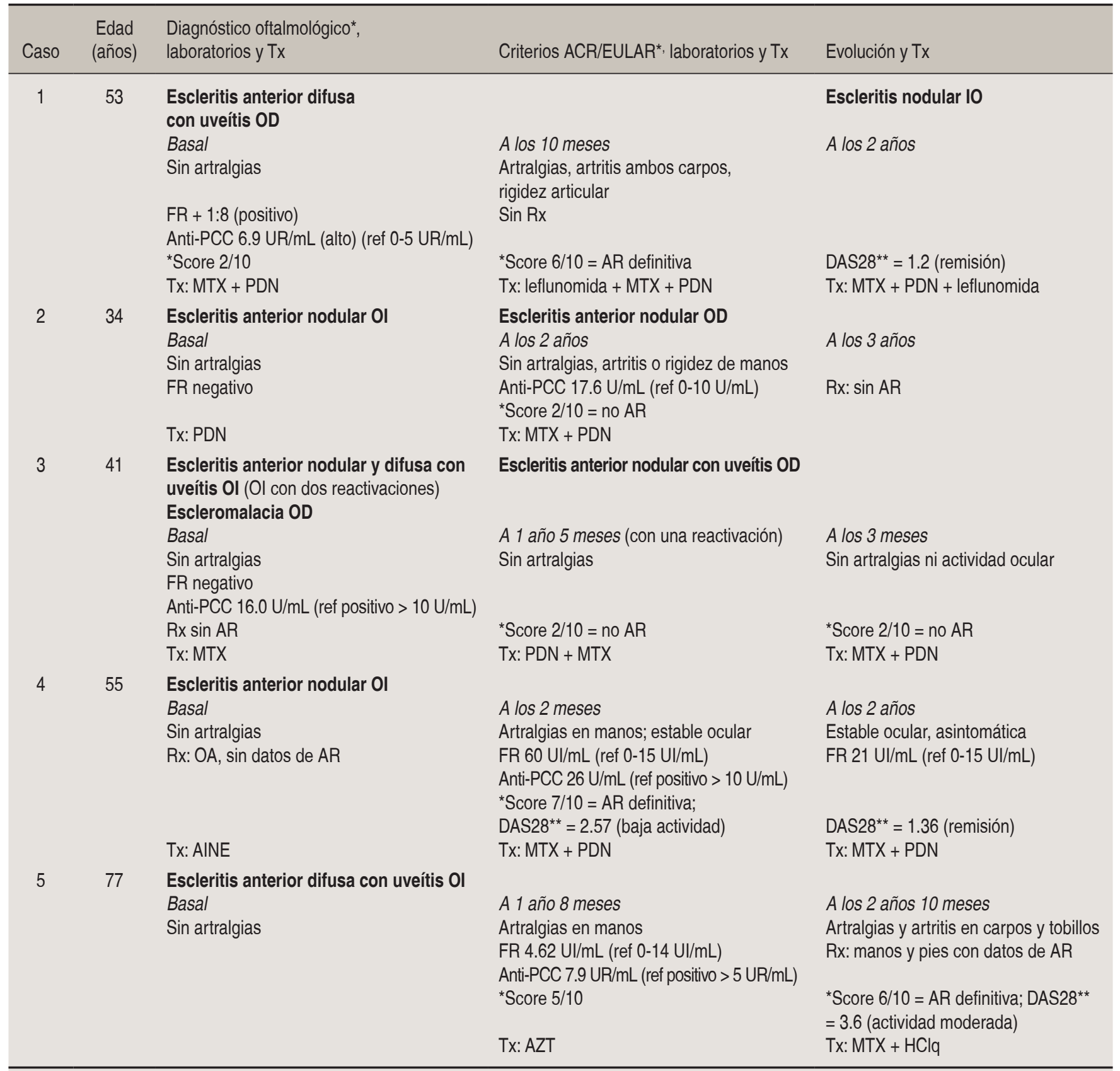

Tx = tratamiento; $\mathrm{OD}=$ ojo derecho; ${ }^{*} \mathrm{ACR} / \mathrm{EULAR}=$ American College of Rheumatology/European League Against Rheumatism; FR = factor reumatoide; Anti-PCC = anticuerpo antipéptido cíclico citrulinado; $\mathrm{MTX}=$ metotrexato; $\mathrm{PDN}=$ prednisona; $\mathrm{Rx}=$ rayos $\mathrm{X} ; \mathrm{AR}=$ artritis reumatoide; $\mathrm{OI}=0 \mathrm{jo}$ izquierdo; ${ }^{* *} \mathrm{DAS28}=$ Disease $A c t i v i t y$ Score; AZT = azatioprina; $\mathrm{HClq}$ = hidroxicloroquina. 


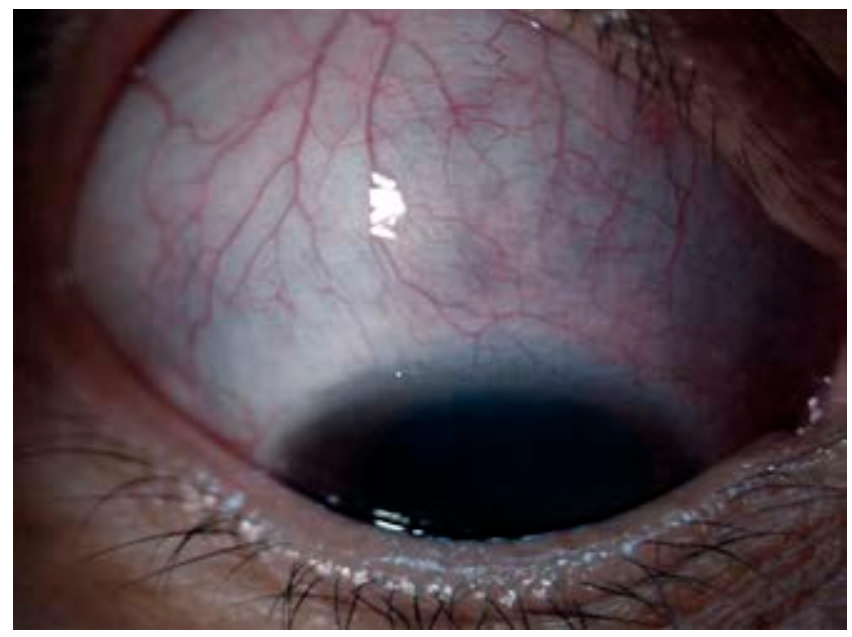

Figura 1: Escleritis anterior difusa, ojo derecho. Se observa dilatación importante de los vasos epiesclerales superficiales y profundos en sector superior, doloroso a la palpación, con hiperemia que no desaparece con la prueba de vasoconstricción (gotas oftálmicas de tropicamida con fenilefrina); se observa midriasis farmacológica secundaria a la aplicación de las gotas.

$\mathrm{mm} / \mathrm{h}$ ) y PCR -, sin cumplir con los criterios de clasificación para AR, por lo que se dejó con diagnóstico de EAD con anti-PCC y FR positivos iniciándose tratamiento con PDN $1 \mathrm{mg} / \mathrm{kg} /$ día vía oral y MTX $10 \mathrm{mg} /$ semana vía oral lográndose la inactivación de la escleritis. A las dos semanas, se inició el descenso gradual de PDN y el incremento de MTX a $15 \mathrm{mg} /$ semana. Diez meses después del ingreso, estando con $7.5 \mathrm{mg} /$ día de PDN, inició con rigidez articular matutina de dos horas, artralgias y artritis en ambos carpos, integrándose el diagnóstico de AR (score ACR/EULAR = 6/10) agregándose al tratamiento leflunomida $20 \mathrm{mg} /$ día, controlando así los síntomas articulares. Un año después presentó un nuevo cuadro de escleritis nodular (EN) en el ojo izquierdo, por lo que se aumenta el MTX a $20 \mathrm{mg} / \mathrm{semana}$ y la PDN a $10 \mathrm{mg} /$ día. En la actualidad, continúa con el mismo tratamiento, se encuentra estable a nivel ocular y articular con un score de la actividad de enfermedad (Disease Activity Score) o DAS28 de 1.2 (remisión) y en espera para iniciar tratamiento con anti-TNF.

Caso 3: mujer de 41 años que consultó por tener un mes con ojo izquierdo rojo, doloroso y con fotofobia. Se hace el diagnóstico de escleritis anterior nodular y difusa con uveítis anterior (EAN + EAD + $\mathrm{UA}=$ esclerouveítis), encontrándose además datos clínicos de escleromalacia en ojo derecho (Figura 2). A la exploración sistémica, sin artralgias ni artritis. Se inicia tratamiento con PDN vía oral a dosis reducción y se solicitan exámenes de laboratorio en- contrándose con anti-PCC elevado $(16 \mathrm{U} / \mathrm{mL})$ y FR - con VSG = $21 \mathrm{~mm} / \mathrm{h}$ (ref 0-15) y PCR -; dos meses después, se decide iniciar tratamiento con MTX vía oral. Después la paciente presentó reactivaciones de la escleritis en ojo izquierdo en dos ocasiones, por lo que ameritó aumento en la dosis de MTX y de PDN; en la segunda reactivación se agregó una inyección de esteroide (betametasona) periocular. Un año y medio después del primer cuadro, acudió refiriendo dolor, ojo rojo y fotofobia ahora en ojo derecho de un mes de evolución, diagnosticándose EAN (Figura 3) + UA (esclerouveítis), por lo que se aumenta dosis de MTX. Meses después se tuvo que modificar la dosis de MTX por elevación de las transaminasas. A nivel sistémico, sigue sin referir manifestaciones articulares (score ACR/EULAR = 2/10); tres años después, el caso presenta nuevamente una reactivación de la escleritis en ojo derecho con dolor y ojo rojo, por lo que tuvo que modificarse el tratamiento. En su última revisión, la paciente se encontraba estable a nivel ocular y continuaba sin manifestaciones articulares con una dosis de MTX $15 \mathrm{mg} / \mathrm{semana}$ vía oral + PDN $7.5 \mathrm{mg} /$ día vía oral teniendo VSG $18 \mathrm{~mm} / \mathrm{h}$ (ref $0-10$ ) y una PCR 1:80 (positiva).

Caso 5: mujer de 77 años con antecedente de DM2, quien consultó por presentar miodesopsias («moscas flotantes»), ojo izquierdo rojo y disminución de agudeza visual. Se hizo diagnóstico de esclerouveítis y se manejó con tratamiento tópico a base de prednisolona a dosis reducción. Se solicitaron estudios de laboratorio para descartar etiología infecciosa y anticuerpos para diagnosticar artritis reumatoide,

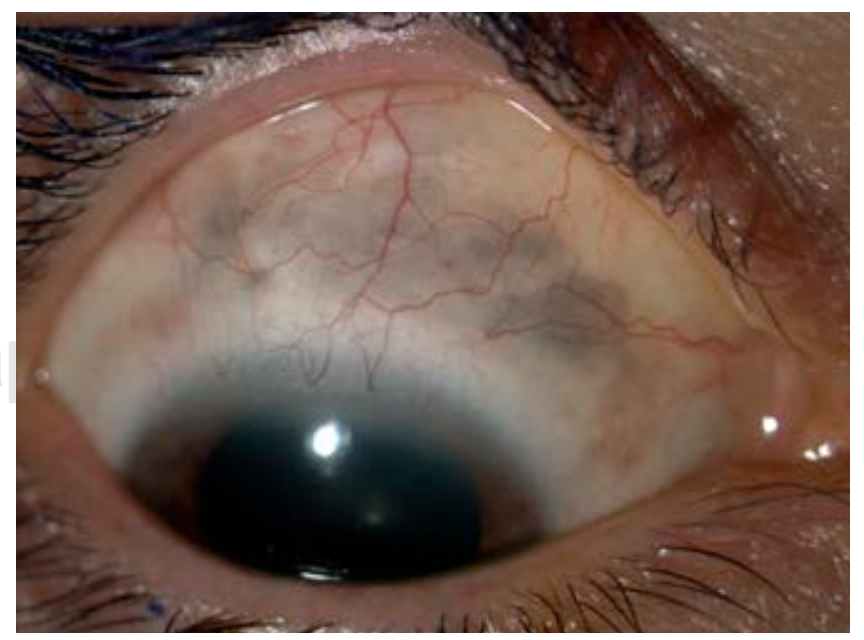

Figura 2: Escleromalacia, ojo derecho. Adelgazamiento escleral en sector superior con la consecuente visualización de la característica coloración violácea de tejido coroideo subyacente; midriasis farmacológica. 


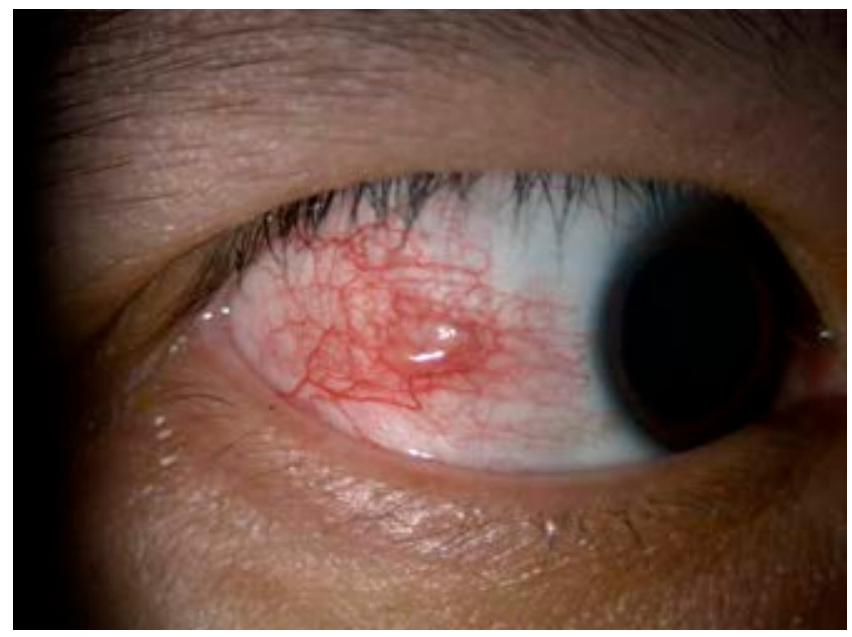

Figura 3: Escleritis anterior nodular, ojo derecho. Se observa nódulo escleral, dilatación de vasos epiesclerales superficiales y profundos en sector temporal, doloroso a la palpación, con hiperemia que no desaparece con la prueba de vasoconstricción (gotas oftálmicas de tropicamida con fenilefrina); se observa midriasis farmacológica secundaria a la aplicación de las gotas.

los cuales fueron negativos. $\mathrm{Al}$ año con ocho meses refiere artralgias de manos con anti-PCC + (7.9 UR/ $\mathrm{mL}$ ) y PCR ligeramente elevada, por lo que se inició tratamiento con azatioprina (AZT) $50 \mathrm{mg} /$ día vía oral y PDN $20 \mathrm{mg} /$ día vía oral a dosis reducción. A los dos años con 10 meses regresa con artralgias y artritis en carpos/tobillos, un score ACR/EULAR = de 6/10 (AR definitiva) y cambios crónicos de AR en las radiografías de manos y pies (Figura 4), con VSG $38 \mathrm{~mm} / \mathrm{h}$ (ref 0-20) y PCR de $10.23 \mathrm{mg} / \mathrm{L}$ (ref 0-5), por lo que se decide cambiar tratamiento (suspendiéndose AZT) e iniciar MTX, presentando actualmente un DAS28 = 3.6 (actividad moderada).

\section{DISCUSIÓN}

En esta serie de casos, tres individuos desarrollaron AR definitiva de acuerdo con los criterios del 2010 ACR/EULAR, después de la manifestación oftalmológica: a los dos meses (score 7/10), a los 10 meses (score $6 / 10$ ) y a los dos años seis meses (score 6/10). Dos pacientes (caso \#1 y \#3) nunca desarrollaron criterios definitivos para AR (score 2/10), ambas a pesar de tener afección ocular bilateral y más de tres años de seguimiento; una de ellas (caso \#3) con recaídas de la inflamación ocular ameritando fármacos modificadores de la enfermedad/FARME (DMARD = diseasemodifying anti-rheumatic drugs) con MTX además de PDN vía oral. El objetivo de lograr una remisión, definida como un score de actividad de la enfermedad
(DAS28 = disease activity score) $<2.6$ se obtuvo en dos pacientes con el tratamiento instaurado quedando sólo el caso \#5 con actividad moderada (DAS28 = 3.6).

Por lo anterior, en la Clínica de Enfermedades Inflamatorias de la APEC sugerimos instaurar tratamiento temprano (fase preartrítica) con FARME tomando en cuenta como signo de riesgo a la escleritis (aunado a los marcadores serológicos y de imagen ya conocidos), para la progresión o desarrollo de AR y poder modular la evolución de la enfermedad; así como la EULAR define «artralgia sospechosa para la progresión a $A R »$ definir a la escleritis de manera similar, estando a favor de lo anterior que estos pacientes responden a tratamientos habituales como MTX. ${ }^{21,22}$

No existe un consenso sobre la importancia y frecuencia con la que se deben pedir los marcadores
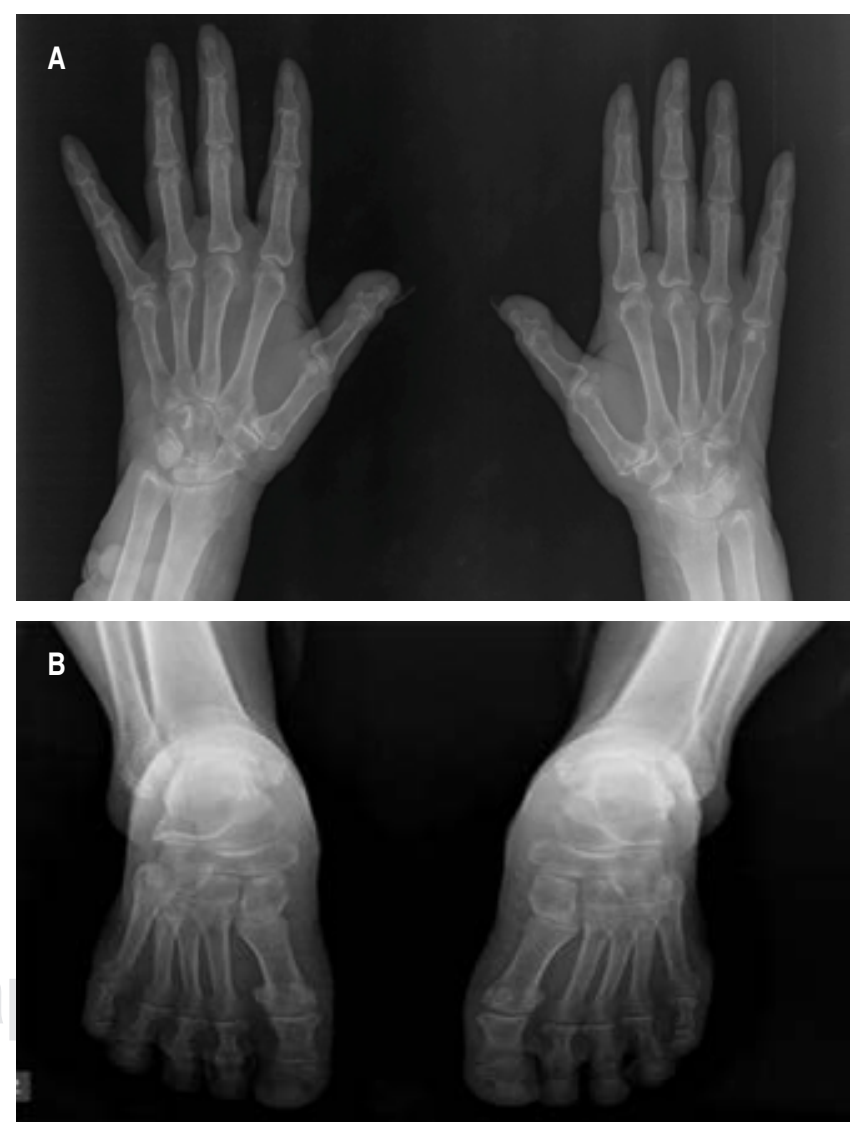

Figura 4: Radiografías. A) Manos (anteroposterior). Adecuada alineación, osteopenia yuxtaarticular, disminución pancompartamental de los huesos del carpo, disminución asimétrica del espacio en interfalángicas distales y proximales. No se observa el proceso estiloideo izquierdo. Tiene datos de osteoartrosis (OA) y tempranos de AR. B) Pies (anteroposterior). Adecuada alineación, osteopenia yuxtaarticular, esclerosis subcondral, erosión en articulación metatarsofalángica derecha e izquierda. 
An Med (Mex) 2020; 65 (4): 262-269

serológicos (FR y anti-PCC) en casos con escleritis idiopáticas que pueden evolucionar a un desarrollo franco de enfermedad sistémica (AR).

En nuestra serie de casos, tres desarrollaron AR en un periodo de tiempo variable (de dos meses hasta dos años y medio) después de haber debutado sólo con escleritis. Lin demostró que aún en pacientes con ausencia de síntomas articulares, la presencia de escleritis idiopática con FR+ aumentaba el riesgo de desarrollo de AR, siendo de los pocos artículos que resaltan la importancia de la escleritis como un probable factor predictivo positivo. ${ }^{23}$

Tres de nuestras pacientes recibieron tratamiento dentro del periodo descrito como de mayor respuesta y asociado con menor incidencia de recaídas a nivel articular ( $\leq 90$ días). ${ }^{24} \mathrm{~A}$ pesar de esto, el caso \#3 presentó varias reactivaciones de la escleritis sin cumplir nunca criterios para AR definitiva, y el caso \#1 presentó escleritis en el ojo contralateral, lo cual demuestra que la presencia de inflamación ocular es un dato de actividad sistémica, y debe ser tomado en cuenta ya sea para el inicio, mantenimiento, aumento o modificación del tratamiento sistémico. Por otro lado, el caso \#5 desarrolló AR varios años posteriores al debut de la escleritis en ojo izquierdo.

La escleritis es una manifestación grave de la enfermedad en pacientes con AR, relacionándose con una menor supervivencia, siendo además considerada dentro de los criterios de manifestaciones extraarticulares de AR como parte de la vasculitis reumatoide. ${ }^{13,17,25}$

Existe una asociación importante entre la duración de la enfermedad con las manifestaciones oculares; a más duración, más comunes y severas. ${ }^{16}$ Lo importante de nuestra serie de casos es que esta asociación se encuentra invertida, ya que desafía el concepto de que la escleritis es una manifestación tardía oftalmológica de una vasculitis reumatoide con AR de larga evolución, pudiendo presentarse mucho tiempo antes de la aparición de las alteraciones articulares.

Sugerimos que aunque no existan alteraciones articulares, la sola presencia de escleritis antes de cualquier otra manifestación extraarticular e independientemente de los resultados serológicos debe recibir tratamiento temprano (con FARME) aunque no se cumplan los criterios de EULAR. ${ }^{26-28}$ Para finalizar, nuestra investigación tiene varias limitantes: serie de casos, retrospectivo, seguimiento corto y falta de apego de los pacientes (para cumplir con sus citas y su tratamiento). Por lo anterior, es probable que el número de casos que debutan con escleritis y anti-PCC + con FR- está subestimado en nuestra población.

\section{CONCLUSIONES}

Con nuestra serie de cinco casos y lo reportado en la literatura, podemos apreciar que la escleritis puede ser la primera manifestación de AR mucho tiempo antes del desarrollo de la enfermedad sistémica. Debemos vigilar de cerca los casos con escleritis que tengan serología negativa para AR, ya que probablemente evolucionen a una franca clínica de AR en meses o años próximos. La presencia de anti-PCC + con FR - toma relevancia en aquéllos que debutan con escleritis idiopática. Es importante el manejo multidisciplinario entre reumatólogos y oftalmólogos con la finalidad de identificar tempranamente a estos casos e instaurar un tratamiento (con FARME) para evitar complicaciones oculares que pongan en riesgo la visión e incidir también en la prevalencia de la enfermedad articular.

\section{AGRADECIMIENTOS}

A las Dras. Yolanda Chávez Romero y Diana Sarmiento Forero para la obtención de las imágenes y recolección de datos, ambas Fellows de la Clínica de Enfermedades Inflamatorias Oculares en la Asociación para Evitar la Ceguera.

\section{BIBLIOGRAFÍA}

1. Lin YJ, Anzaghe M, Schülke S. Update on the pathomechanism, diagnosis, and treatment options for rheumatoid arthritis. Cells. 2020; 9 (4): 880.

2. Smolen JS, Aletaha D, McInnes IB. Rheumatoid arthritis. Lancet. 2016; 388 (10055): 2023-2038.

3. Yener A, Şahin K. The association of choroidal thickness with rheumatoid factor and anti-cyclic citrullinated peptide in rheumatoid arthritis. Int Ophthalmol. 2020; 40 (4): 935-941.

4. Boman A, Brink M, Lundquist A, Hansson M, Mathsson-Alm L, Rönnelid J et al. Antibodies against citrullinated peptides are associated with clinical and radiological outcomes in patients with early rheumatoid arthritis: a prospective longitudinal inception cohort study. RMD Open. 2019; 5 (2): e000946.

5. Bugatti S, Manzo A, Montecucco C, Caporali R. The clinical value of autoantibodies in rheumatoid arthritis. Front Med (Lausanne). 2018; 5: 339.

6. Brink M, Hansson M, Mathsson-Alm L, Wijayatunga P, Verheul MK, Trouw LA et al. Rheumatoid factor isotypes in relation to antibodies against citrullinated peptides and carbamylated proteins before the onset of rheumatoid arthritis. Arthritis Res Ther. 2016; 18: 43.

7. Yap HY, Tee SZ, Wong MM, Chow SK, Peh SC, Teow SY. Pathogenic role of immune cells in rheumatoid arthritis: implications in clinical treatment and biomarker development. Cells. 2018; 7 (10): 161.

8. Nishimura K, Sugiyama D, Kogata Y, Tsuji G, Nakazawa T, Kawano $\mathrm{S}$ et al. Meta-analysis: diagnostic accuracy of anticyclic citrullinated peptide antibody and rheumatoid factor 
for rheumatoid arthritis. Ann Intern Med. 2007; 146 (11): 797-808.

9. Llopis E, Kroon HM, Acosta J, Bloem JL. Conventional radiology in rheumatoid arthritis. Radiol Clin North Am. 2017; 55 (5): 917-941.

10. Lee DM, Schur PH. Clinical utility of the anti-CCP assay in patients with rheumatic diseases. Ann Rheum Dis. 2003; 62 (9): 870-874.

11. Aggarwal R, Liao K, Nair R, Ringold S, Costenbader KH. Anti-citrullinated peptide antibody assays and their role in the diagnosis of rheumatoid arthritis. Arthritis Rheum. 2009; 61 (11): 1472-1483.

12. Marcucci E, Bartoloni E, Alunno A, Leone MC, Cafaro G, Luccioli $\mathrm{F}$ et al. Extra-articular rheumatoid arthritis. Reumatismo. 2018; 70 (4): 212-224.

13. Turesson C, Jacobsson L, Bergström U. Extra-articular rheumatoid arthritis: prevalence and mortality. Rheumatology (Oxford). 1999; 38 (7): 668-674.

14. Okhravi N, Odufuwa B, McCluskey P, Lightman S. Scleritis. Surv Ophthalmol. 2005; 50 (4): 351-363.

15. Nevares A, Raut R, Libman B, Hajj-Ali R. Noninfectious autoimmune scleritis: recognition, systemic associations, and therapy. Curr Rheumatol Rep. 2020; 22 (4): 11.

16. Vignesh AP, Srinivasan R. Ocular manifestations of rheumatoid arthritis and their correlation with anti-cyclic citrullinated peptide antibodies. Clin Ophthalmol. 2015; 9: 393-397.

17. McGavin DD, Williamson J, Forrester JV, Foulds WS, Buchanan WW, Dick WC et al. Episcleritis and scleritis. A study of their clinical manifestations and association with rheumatoid arthritis. Br J Ophthalmol. 1976; 60 (3): 192-226.

18. Artifoni M, Rothschild PR, Brézin A, Guillevin L, Puéchal $\mathrm{X}$. Ocular inflammatory diseases associated with rheumatoid arthritis. Nat Rev Rheumatol. 2014; 10 (2): 108-116.

19. Prevoo ML, van't Hof MA, Kuper HH, van Leeuwen MA, van de Putte LB, van Riel PL. Modified disease activity scores that include twenty-eight-joint counts. Development and validation in a prospective longitudinal study of patients with rheumatoid arthritis. Arthritis Rheum. 1995; 38 (1): 44-48.
20. Aletaha D, Neogi T, Silman AJ, Funovits J, Felson DT, Bingham CO et al. 2010 Rheumatoid arthritis classification criteria: an American College of Rheumatology/European League Against Rheumatism collaborative initiative. Arthritis Rheum. 2010; 62 (9): 2569-2581.

21. van Steenbergen HW, da Silva JAP, Huizinga TWJ, van der Helm-van Mil AHM. Preventing progression from arthralgia to arthritis: targeting the right patients. Nat Rev Rheumatol. 2018; 14 (1): 32-41.

22. van der Helm-van Mil AH, Zink A. What is rheumatoid arthritis? Considering consequences of changed classification criteria. Ann Rheum Dis. 2017; 76 (2): 315-317.

23. Lin P, Bhullar SS, Tessler HH, Goldstein DA. Immunologic markers as potential predictors of systemic autoimmune disease in patients with idiopathic scleritis. Am J Ophthalmol. 2008; 145 (3): 463-471.

24. Kempen JH, Pistilli M, Begum H, Fitzgerald TD, Liesegang TL, Payal A et al. Remission of non-infectious anterior scleritis: incidence and predictive factors. Am J Ophthalmol. 2019: S0002-9394(19)30134-5.

25. Bettero RG, Cebrian RF, Skare TL. Prevalence of ocular manifestation in 198 patients with rheumatoid arthritis: a retrospective study. Arq Bras Oftalmol. 2008; 71 (3): 365-369.

26. Nordberg LB, Lillegraven S, Lie E, Aga AB, Olsen IC, Hammer HB et al. Patients with seronegative RA have more inflammatory activity compared with patients with seropositive RA in an inception cohort of DMARD-naïve patients classified according to the 2010 ACR/EULAR criteria. Ann Rheum Dis. 2017; 76 (2): 341-345.

27. Nordberg LB, Lillegraven S, Aga AB, Sexton J, Olsen IC, Lie E et al. Comparing the disease course of patients with seronegative and seropositive rheumatoid arthritis fulfilling the $2010 \mathrm{ACR} /$ EULAR classification criteria in a treat-to-target setting: 2-year data from the ARCTIC trial. RMD Open. 2018; 4 (2): e000752.

28. Bogdanic-Werner K, Fernandez-Sanz G, Alejandre Alba N, Ferrer Soldevila P, Romero-Bueno FI, Sanchez-Pernaute O. Rituximab therapy for refractory idiopathic scleritis. Ocul Immunol Inflamm. 2013; 21 (4): 329-332. 